\title{
The impact of lower-limb prosthetic limb use in international C4 track para-cycling
}

An investigation was undertaken to ascertain any impact or significance of athletes within the $\mathrm{C} 4$ paracycling classification between those who use a lowerlimb prostheses and those who do not. A statistical evaluation of event completion time was undertaken to assess $\mathrm{C} 4$ cyclists when competing at the World Championships and the Paralympic Games in the $1 \mathrm{~km}$ track time trial.

The C4 athletes who utilise a prostheses consistently outperformed non-amputees in the C4 classification from 2011-2016 on a competition-to-competition basis. However, when the participations were grouped as a whole together and an identified outlier athlete was removed, it was then demonstrated that there was no statistical significance between those who required the use of a lower-limb prostheses to those that did not when either evaluated on a competition-bycompetition or on an amputee and non-amputee group-by-group basis $(P=>0.05)$. As a result, this study proposes that those requiring the use of lower-limb prostheses are neither advantaged nor disadvantaged in the C4 classification category when competing in the $1 \mathrm{~km}$ time trial at this time.

\section{Implications for Rehabilitation}

- This analysis indicates that at this time, there is no evidence to suggest that use of such technology is advantageous in this category or should be seen as controversial.

- The design of lower-limb prosthetic limb technology in cycling should continue to be developed and optimized unabated.

- This study begins to address the cited lack of peer reviewed information regarding paracycling with limb absence available to practitioners. 
Keywords: cycling; prostheses; performance enhancement

\section{Introduction}

Cycling with an amputated limb has evolved as an activity from one of purely recreation [1] into international-level competition [2]. Competitive cycling that is held within the formalised framework of sport with a disability requires that pools of athletes are categorised based upon an assessment of their functionality [3] and therefore not the generalised type of their disability. As a result, cyclists with an amputation could potentially compete directly against those with different disabilities within the same category. At competitions like the World Championships or the Paralympic Games, the typical classifications that such athletes will be included in would be those designated C1, C2, C3, C4 or C5. The specification for each of these and any assistive technology required is clearly defined (http://www.uci.ch/mm/Document/News/Rulesandregulation/16/26/73/16-PAR20160501-E_English.PDF). However, it could be argued that the potential wide range of disabilities contained within a classification could lead to a fundamental unfairness [4] or alternatively provide mechanical ergogenic opportunity to those currently using inferior assistive technology [5].

To undertake cycling whilst possessing any level of lower-limb amputation will likely require some form of specialised prostheses to be developed. This technology provides a unique visible distinction between those who have lost a limb and those that have not. This type of assistive technology is not currently heavily regulated by the sports current rules or the aesthetic limitations of a biological limb. 
Whilst the aerodynamic performance of cycling prosthetic limbs have seen an initial investigation [6] and their hypothetical impact proposed [5], there has been little attention to date of the actual impact of lower-limb prostheses when worn by an athlete with an amputation. However, it has been proposed that the aerodynamics of a lowerlimb prosthesis could be made advantageous over the equivalent biological limb region [5]. In addition, an effective prostheses design could aid in the athletes power transfer efficiency [7] and this is of value when undertaking time trials with a view to producing the best possible performance [8].

In this paper, a statistical evaluation of C4 para-cycling is undertaken to ascertain the differences between those participating within this classification category utilising a lower-limb prostheses from those that do not. This preliminary investigation may offer some insight into the often debated impact of such assistive or adaptive technology.

\section{Methods}

\section{Statistical evaluation}

The $1 \mathrm{~km}$ time trial is an event requiring the athlete to start from a fixed start gate and then to perform four laps of a $250 \mathrm{~m}$ velodrome as quickly as possible. The results of the $1 \mathrm{~km}$ time trial from the UCI World Paracycling Track Championships were evaluated from 2011-2016. Whilst other individually timed events (such as the 3km Individual Pursuit or the outdoor Individual Time Trial) could also potentially be utilised for this study, they could not be investigated in this case due to inconsistent levels of annual participation or the impact of annual changes in their course topography or climatic conditions. It should also be noted that no $1 \mathrm{~km}$ championships took place in 2013. In addition, due to its sporting importance and its relatively large sample of athletes 
participating, an assessment of the results from the Paralympic Games from 2012 and 2016 were also included in this study. Unlike the World Championships, a combined racing category comprising both C4 and C5 category athletes took place at the Paralympic Games and a percentage time adjustment process (known as factoring) was used to handicap one over the other. Whilst the current factored adjustment is outlined within the sports regulations, it could not be confirmed whether this value had been the same value in the past. As a result, since the factoring adjustment between the C4 and C5 times in both games in the long term could not be reliably verified, the Paralympic Games were reviewed in isolation to the World Championships for the purposes of this study.

The male C4 classification category formed the sole basis of this papers investigation. Whilst amputees do also compete in the C2 and C3 categories (as well as those who are female), an initial review of the results showed that these were either too small in number or too inconsistent in participation frequency to be evaluated in this study. The race data results were sourced from the public domain and were taken from the official International Paralympic Committee website (www.paralympic.org). In each competition, the athletes were split into one of two sub-groups. These were all from the C4 classification event and were designated amputee competitors (AC-C4) or other competitors (OC-C4). The nature of each competitor's disability was identified by using photographic evidence sourced from the internet, social media or using any available video footage of their competitions. Multiple sources of evidence were used to corroborate whether an athlete was a lower-limb amputee or not and also required the use of a prosthetic limb. Two athletes could not be reliably identified so were therefore decided to be included in the OC-C4 category.

Five types of data analysis took place. These included: 
- An analysis of the participation level of AC-C4 and OC-C4 competitors from 2011-16.

- A comparison of the AC-C4 and OC-C4 competitors in the World Championship and (separately) the Paralympic Games.

- A comparison of the fastest three AC-C4 and OC-C4 competitors in each World Championship and Paralympic Games. This was based on making an elitist assumption that other athletes below these could be in the early (or declining) stages of their athletic career and their slower performances (if included) could skew the results.

- To increase the statistical power of the sample, a comparison of the AC-C4 and OC-C4 competitors when all of the separate $1 \mathrm{~km}$ rides performed at all of the World Championships were combined together in their respective AC-C4 and OC-C4 groups (and likewise for the Paralympic Games). Whilst some of these performances would be undertaken by the same riders over the course of their athletic careers, this analysis was intended to take a greater overview of the sport as a whole and would have the advantage of a greater dataset than those from each individual championship alone.

- A comparison of the AC-C4 and OC-C4 competitors are made when all of the separate rides performed at all of the World Championships were combined together in their respective AC-C4 and OC-C4 groups (and likewise for the Paralympic Games) but with the removal of a perceived outlier athlete. The athlete in question is a C4 paracyclist, world record holder and (aside for a single event disqualification due to a starting infraction at the Paralympic Games in 2012), typically won by relatively large margins. 
The means and standard deviations of all three analyses were reported. A statistical evaluation of sub-group differences in calculated means has been used before to indicate if one type of disability may have any consistent advantage over another when they both compete within the same event [9]. As a result, the two-tailed $t$-test was used to compare the means of the AC-C4 and OC-C4 groups from within the $\mathrm{C} 4$ para-cycling classification from 2011-2016. To determine the level of sub-group data variability, an $F$-test was performed prior to each $t$-test. The level of significance of the $t$-tests was set as $p=<0.05$.

\section{Results}

\section{Statistical evaluation}

The level of participation from 2011-16 between the AC-C4 and OC-C4groups is shown in figure 1.

\section{[INSERT FIGURE 1]}

The AC-C4 group has always seen a lower level of participation than that of the OC-C4 groups with the exception of the 2012 Paralympic Games. In addition, the Paralympic Games appears to attract a lower number of competing athletes than that of the annual World Championships.

A summary of the athletic performance of the AC-C4 and OC-C4 groups are shown in table 1.

[INSERT TABLE 1] 
In all of the World Championships, the AC-C4 group had a lower mean average (and were therefore faster) as a type than the OC-C4 group. In this case, the full field results at the World Championships in 2015 demonstrated a statistically significant difference between the AC-C4 and OC-C4 athletes $(p<0.05)$. In addition, the championships in 2011 and 2014 demonstrated that they were very close to achieving the targeted level of statistical significance $(p=0.06)$. However, the top three results comparison demonstrated no championships that indicated a successful level of significance between the AC-C4 and OC-C4 groups. However, this was a marginal statistical outcome in $2012(p=0.06)$.

The results of the Paralympic Games are shown in table 2.

\section{[INSERT TABLE 2]}

Both Paralympic Games did not indicate any significant different between the AC-C4 and OC-C4 group's results. In 2012, the AC-C4 group were marginally slower than the OC-C4 groups. Conversely, in 2016, the OC-C4 group were slower than the AC-C4 group.

When the separate rides from all of the World Championships are pooled together (and likewise for the Paralympic Games), the results are shown in table 3.

\section{[INSERT TABLE 3]}

The pooled results from the World Championships demonstrate a clear level of statistical significance of the AC-C4 group from the OC-C4 group. However, the 
Paralympic Games do not reflect the same behaviour. The coefficient of variation of the finishing times of both the AC-C4 and OC-C4 groups were 6\% thereby demonstrating the same level of data variability.

When the separate rides from all of the World Championships are pooled together (and likewise for the Paralympic Games), but with the outlier athlete removed from the data, the results are shown in table 4.

[INSERT TABLE 4]

The pooled results from the World Championships with the outlier athlete removed do not demonstrate a level of statistical significance of the AC-C4 group from the OC-C4 group ( $\mathrm{P}=>0.05$ ). This suggests that the performance of this one athlete has a notable bearing on the performance of the AC-C4 athletes as a whole. The coefficient of variation of this data set fell from $6 \%$ (with outlier) to $5 \%$ (without outlier).

\section{Discussion}

The statistical analysis revealed that those in the C4 category that required the use of a prosthetic limb had on all occasions (barring one), achieved a mean average that was superior in event completion time performance to those that did not require one. Only the World Championships in 2015 demonstrated a clear statistical significance between the AC-C4 and OC-C4 groups. Three other championships demonstrated a difference in mean performance that was very close to achieving the required level of significance. It could be argued that due to the marginal completion times of one athlete over another and that the events completion time is recorded to three decimal places, that a non-norm level of statistical significance could be recommended for use in this case. Such an 
approach has been adopted in other sporting events such as sprint kayaking [10]. In the kayaking study, a unique level of significance of 0.1 had been selected instead of the typical 0.05 norm. However, it was not clear how this exact value was derived and as a result could be seen as an arbitrary decision. Subsequently, this practice was considered but not adopted for this paper. Ultimately, it is recommended that the marginally statistically insignificant results should not be entirely disregarded in this study but that further investigation may provide evidence of what level of significance should be used for events such as the $1 \mathrm{~km} \mathrm{TT}$.

There was a large difference in statistical significance between the World Championships and the Paralympic Games when all of the rides were combined together and pooled into their two respective groups. It could be proposed that any factoring calculation (that is only applied at the Paralympic Games) is affecting or masking the differences that were detected from the World Championships datasets. However, it is felt that the reasons for this difference became more obvious when the C4 outlier athlete was removed from the datasets. When this was undertaken, neither the best three athletes nor the inclusion of the whole group yielded a statistical difference between the AC-C4 and OC-C4 groups. In these cases, whilst the mean average completion time of the AC-C4 was still superior to the OC-C4 at the Paralympic Games, it was not at the World Championships. It is proposed that the outlier athlete is a physiologically superior athlete compared to their peers, irrespective of the nature or level of their disability. It cannot be commented whether there are other athletes within the datasets who might be more negatively affected by the level of their lower-limb amputation. To date, the formal evaluation of such athletes has been extremely limited and has relied on a case study approach $[11,12]$. In these cases, the athletes have been at least 37 years of age and their 'elite' status was defined by what they have won or 
whether they are a professional athlete. This makes any findings extremely limited and not directly transferrable to the athletes in this study.

Whilst the event takes place over four laps, it is conceded that the rider may well be in a standing position for a significant proportion of lap one. This would thereby alter the proportion of aerodynamic drag a prosthetic limb may possess from lap one to laps 2-4 and this would likely influence the completion time data in this study more than if the event was a longer time trial. Whilst it has been proposed that the completion time of a 1000 metre time trial may well be influenced by both aerodynamic drag and the rider's power output [8], this works off the assumption that an athlete with a lower-limb amputation will perform the event in the same way as an able-bodied athlete. However, the much longer completion times of those seen in the C4 category compared to the able-bodied equivalent can be as great as an additional 50\%. As a result, it cannot be assumed that the same energetic or pacing strategies are being employed by $\mathrm{C} 4$ athletes. It is also possible that the mean differences in performance in this paper may not be solely due to a prosthesis aerodynamic drag but may also be due to the efficiency of the athletes power transfer from themselves, through the prosthetic limb and ultimately to the pedals. As a result, the design of such limbs should consider not only the aerodynamic form but also the mechanical structure of such technology. This study proposes that the mixed disability in this category and event does not at this time highlight any discrepancy between those who use a lower-limb prosthesis and those that do not. However, this study cannot say that the use of such technology is of no value. Other studies have highlighted that a basis for performance enhancement could exist [6]. Instead it is proposed that the physiologically capabilities are of greater importance and this has been noted in a related study before when evaluating other paracycling classifications [13]. 
However, if such technology is found to demonstrate significant performance enhancement in the future, it may be in the interests of the governing body to employ some form of legislation to limit their design. This could involve limiting the aspect ratio of any aerofoil or by having a standardized method of matching the diameter of the prosthetic limbs shank or pylon against a rider’s remaining biological limb.

\section{Conclusions}

The performance of athletes who do and do not require the use of a lower limb prostheses were compared when competing at the World Paracycling Track Championships and the Paralympic Games from 2011-16. The athletes that required the use of lower-limb prostheses in the C4 classification typically completed the event faster than those not requiring one. However, when an athlete that was considered an outlier was removed from the data during this time period, the results suggested that there was no statistical significance between those who required the use of a lower-limb prosthesis to those that did not when either evaluated on a competition-by-competition basis or on a group-by-group basis. As a result, this study proposes that those requiring the use of a lower-limb prosthetic limb are neither advantaged nor disadvantaged in the C4 classification category when competing in the $1 \mathrm{~km}$ time trial.

Word Count: 3256

\section{Declaration of Interest}

The authors report no conflicts of interest

\section{References}


1. Legro MW, Reiber GE, Czerniecki JM, Sangeorzan BJ. Recreational activities of lower-limb amputees with prostheses. Journal of Rehabilitation Research and Development. 2001; 38: 319-325.

2. Dyer B. Cycling with an amputation: a systematic review. Prosthetics and Orthotics International. 2015; DOI: 10.1177/0309364615610659.

3. Tweedy SM, Vanlandewijck YC. International Paralympic Committee position stand-background and scientific principles of classification in Paralympic sport. British Journal of Sports Medicine. 2011; 45: 259-69.

4. Dyer B. An insight into the use and assessment of lower limb running prostheses in sport with a disability: A mixed method approach. Cogent Engineering. 2016; 31: DOI.org/10.1080/23311916.2016.1158488.

5. Childers WL, Gallagher TP, Duncan JC, Taylor DK. Modeling the effect of a prosthetic limb on 4-km pursuit performance. International Journal of Sports Physiology \& Performance. 2015; 10: 3-10.

6. Dyer B. The importance of aerodynamics for prosthetic limb design used by competitive cyclists with an amputation: an introduction. Prosthetics and Orthotics International. 2015; 39: 232-7.

7. Dyer B, Woolley H. Development of a high-performance transtibial cycling-specific prosthesis for the London 2012 Paralympic Games. Prosthetics and Orthotics International. 2016; DOI 20:0309364616682386.

8. Martin J, Gardner S, Barras M, Martin D. Modelling sprint cycling using fieldderived parameters and forward integration. Medicine \& Sport in Sports \& Exercise. 2006;38: 592-597.

9. Hassani H, Ghodsi M, Shadi M, Noroozi S, Dyer B. An overview of the running performance of athletes with lower-limb amputation at the Paralympic Games 20042012. Sports. 2015; 16:103-15.

10. Robinson M, Holt L, Pelham T. An assessment of hydrodynamic and simulated race performance features of three C-1 hull designs. Human Movement. 2013;14: 322-7. 
11. Menaspà P, Rampinini E, Tonetti L, Bosio A. Physical fitness and performances of an amputee cycling World Champion: a case study. International Journal of Sports Physiology and Performance. 2012; 7: 290-4.

12. Koutny D, Palousek D, Stoklasek P, Rosicky J, Tepla L, Prochazkova M, Svoboda Z, Krejci P. The biomechanics of cycling with a transtibial prosthesis: a case study of a professional cyclist. Int J Med, Health, Pharm Biomed Eng. 2013; 7: 535-540.

13. Leprêtre P, Weissland T, Slawinski J, Lopes P. Para-cycling performance was rather limited by physiological than functional factors. Frontiers in Physiology. 2012; 3:327. 
Table 1. C4 1km TT World Championship performance.

Full Field

Top 3

\begin{tabular}{|c|c|c|c|c|c|c|c|c|}
\hline Year & $\begin{array}{l}\text { AC-C4 } \\
\text { Mean Time } \\
\text { (secs) }\end{array}$ & $\begin{array}{l}\text { OC-C4 Mean } \\
\text { Time (secs) }\end{array}$ & $\begin{array}{l}F \text {-test } \\
\text { outcome }\end{array}$ & $\begin{array}{l}t \text {-test } \\
P\end{array}$ & $\begin{array}{l}\text { AC-C4 } \\
\text { Mean } \\
\text { Time (secs) }\end{array}$ & $\begin{array}{l}\text { OC-C4 Mean } \\
\text { Time (secs) }\end{array}$ & $\begin{array}{l}\text { F-test } \\
\text { outcome }\end{array}$ & $\begin{array}{l}t \text {-test } \\
P\end{array}$ \\
\hline 2011 & $70.90^{ \pm 3.50}$ & $75.19^{ \pm 5.29}$ & $\begin{array}{l}\text { Equal } \\
\text { variance }\end{array}$ & 0.06 & $68.24^{ \pm 2.68}$ & $69.68^{ \pm 1.73}$ & $\begin{array}{l}\text { Equal } \\
\text { variance }\end{array}$ & 0.48 \\
\hline 2012 & $72.47^{ \pm 3.95}$ & $74.43^{ \pm 3.38}$ & $\begin{array}{l}\text { Equal } \\
\text { variance }\end{array}$ & 0.25 & $68.11^{ \pm 1.84}$ & $71.00^{ \pm 0.52}$ & $\begin{array}{l}\text { Equal } \\
\text { variance }\end{array}$ & 0.06 \\
\hline 2014 & $65.49^{ \pm 2.98}$ & $69.23^{ \pm 3.00}$ & $\begin{array}{l}\text { Equal } \\
\text { variance }\end{array}$ & 0.06 & $64.51^{ \pm 2.75}$ & $66.25^{ \pm 0.54}$ & $\begin{array}{l}\text { Unequal } \\
\text { variance }\end{array}$ & 0.40 \\
\hline 2015 & $68.39^{ \pm 3.55}$ & $72.83^{ \pm 3.45}$ & $\begin{array}{l}\text { Equal } \\
\text { variance }\end{array}$ & 0.04 & $66.99^{ \pm 2.66}$ & $69.26^{ \pm 0.24}$ & $\begin{array}{l}\text { Unequal } \\
\text { variance }\end{array}$ & 0.28 \\
\hline 2016 & $70.84^{ \pm 4.34}$ & $72.79^{ \pm 5.60}$ & $\begin{array}{l}\text { Equal } \\
\text { variance }\end{array}$ & 0.43 & $67.28^{ \pm 3.41}$ & $68.89^{ \pm 0.26}$ & $\begin{array}{l}\text { Unequal } \\
\text { variance }\end{array}$ & 0.50 \\
\hline
\end{tabular}

Table 2. C4 1km TT Paralympic Games performance.

\begin{tabular}{|c|c|c|c|c|c|c|c|c|}
\hline & Full Field & & & & Top 3 & & & \\
\hline Year & $\begin{array}{l}\text { AC-C4 } \\
\text { Mean Time } \\
\text { (secs) }\end{array}$ & $\begin{array}{l}\text { OC-C4 Mean } \\
\text { Time (secs) }\end{array}$ & $\begin{array}{l}F \text {-test } \\
\text { outcome }\end{array}$ & $\begin{array}{l}t \text {-test } \\
p\end{array}$ & $\begin{array}{l}\text { AC-C4 } \\
\text { Mean } \\
\text { Time (secs) }\end{array}$ & $\begin{array}{l}\text { OC-C4 Mean } \\
\text { Time (secs) }\end{array}$ & $\begin{array}{l}\text { F-test } \\
\text { outcome }\end{array}$ & $\begin{array}{l}t \text {-test } \\
p\end{array}$ \\
\hline 2012 & $72.70^{ \pm 2.60}$ & $71.02^{ \pm 3.20}$ & $\begin{array}{l}\text { Equal } \\
\text { variance }\end{array}$ & 0.36 & $70.55^{ \pm 1.14}$ & $69.03^{ \pm 0.20}$ & $\begin{array}{l}\text { Unequal } \\
\text { variance }\end{array}$ & 0.15 \\
\hline 2016 & $66.58^{ \pm 3.91}$ & $69.67^{ \pm 2.68}$ & $\begin{array}{l}\text { Equal } \\
\text { variance }\end{array}$ & 0.17 & $65.16^{ \pm 3.28}$ & $67.73^{ \pm 0.40}$ & $\begin{array}{l}\text { Unequal } \\
\text { variance }\end{array}$ & 0.31 \\
\hline
\end{tabular}


Table 3. C4 1km TT Overall ride performance.

\begin{tabular}{|c|c|c|c|c|c|c|}
\hline & Full Field & & & Top 3 & & \\
\hline Competition & $\begin{array}{l}\text { AC-C4 } \\
\text { Mean } \\
\text { Time } \\
\text { (secs) }\end{array}$ & $\begin{array}{l}\text { OC-C4 } \\
\text { Mean } \\
\text { Time } \\
\text { (secs) }\end{array}$ & $\begin{array}{l}t \text {-test } \\
p\end{array}$ & $\begin{array}{l}\text { AC-C4 } \\
\text { Mean } \\
\text { Time } \\
\text { (secs) }\end{array}$ & $\begin{array}{l}\text { OC-C4 } \\
\text { Mean } \\
\text { Time } \\
\text { (secs) }\end{array}$ & $\begin{array}{l}t- \\
\text { test } \\
p\end{array}$ \\
\hline $\begin{array}{l}\text { World } \\
\text { Championships }\end{array}$ & $70.32^{ \pm 4.20}$ & $73.17^{ \pm 4.73}$ & 0.004 & $67.02^{ \pm 2.68}$ & $69.02^{ \pm 1.77}$ & 0.02 \\
\hline $\begin{array}{l}\text { Paralympic } \\
\text { Games }\end{array}$ & $70.25^{ \pm 4.32}$ & $70.29^{ \pm 2.88}$ & 0.98 & $67.86^{ \pm 3.68}$ & $68.38^{ \pm 0.76}$ & 0.74 \\
\hline
\end{tabular}

Table 4. C4 1km TT Overall ride performance (outlier removed).

\begin{tabular}{lllllll} 
& \multicolumn{2}{c}{ Full Field } & \multicolumn{5}{c}{ Top 3 } \\
\hline Competition & $\begin{array}{l}\text { AC-C4 } \\
\text { Mean } \\
\text { Time } \\
\text { (secs) }\end{array}$ & $\begin{array}{l}\text { OC-C4 } \\
\text { Mean } \\
\text { Time } \\
\text { (secs) }\end{array}$ & $\begin{array}{l}\boldsymbol{t} \text { - } \\
\text { test }\end{array}$ & $\begin{array}{l}\text { AC-C4 } \\
\text { Mean } \\
\text { Time } \\
\text { (secs) }\end{array}$ & $\begin{array}{l}\text { OC-C4 } \\
\text { Mean } \\
\text { Time } \\
\text { (secs) }\end{array}$ & $\begin{array}{l}\text { t- } \\
\text { test } \\
\boldsymbol{p}\end{array}$ \\
\hline $\begin{array}{l}\text { World } \\
\text { Championships }\end{array}$ & $71.47^{ \pm 3.49}$ & $73.17^{ \pm 4.73}$ & 0.06 & $69.19^{ \pm 2.14}$ & $69.02^{ \pm 1.77}$ & 0.81 \\
\hline $\begin{array}{l}\text { Paralympic } \\
\text { Games }\end{array}$ & $71.12^{ \pm 3.55}$ & $70.29^{ \pm 2.88}$ & 0.98 & $69.25^{ \pm 2.68}$ & $68.38^{ \pm 0.76}$ & 0.47 \\
\hline
\end{tabular}




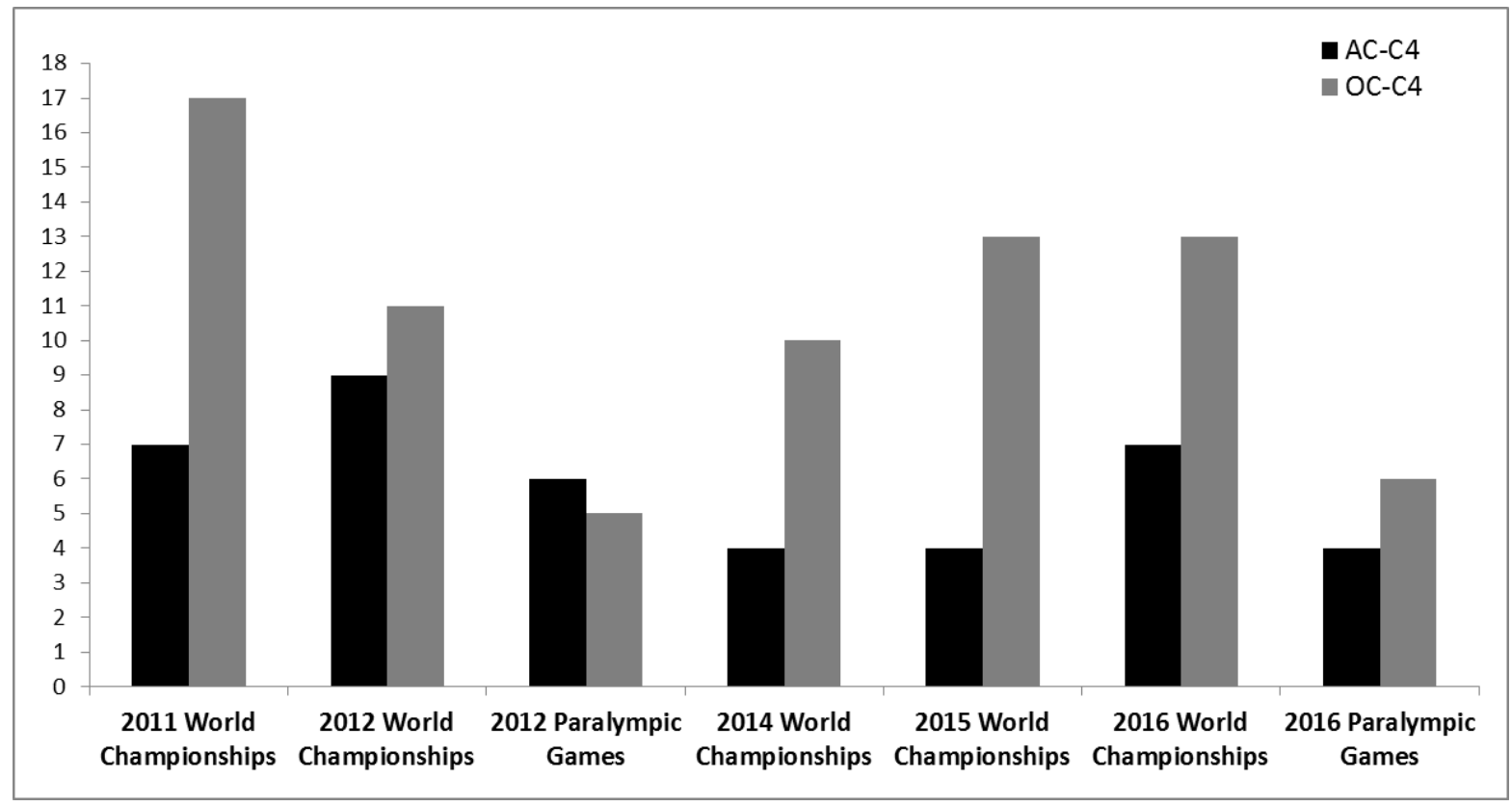

Figure 1. AC-C4 and OC-C4 participation levels. 